\title{
16th Meeting of the Italian Primatological Society
}

\author{
Held at Convento dell'Osservanza, Radicondoli (SI) \\ October 28-30, 2003
}

Guest Editors: D. Formenti, A. Vitale

\section{Opening Lecture}

\section{The Binocular and the Mirror. Anthropomorphism between Ethology and Ethics: A Working Agenda}

\author{
Simone Pollo \\ Dip. di Studi filosofici ed epistemologici, Univ. Roma 'La Sapienza', Via Carlo Fea 2, \\ 00161 Rome, Italy \\ E-Mail simone.pollo@libero.it
}

\section{Key Words: Anthropomorphism • Animal ethics • Animal welfare • Ethology}

Good ethologists are aware of the risks that arise from the tendency to be anthropomorphic about the behaviour of the animals they study. Therefore, it is clear that a distance should be maintained between the ethologist and his/her study animal. This distance seems to be an indispensable requirement for researchers to be able to understand their study animals and to interpret their behaviour. Ethologists are, therefore, warned against projecting specific human traits onto animals. But, paradoxically, the possibility of considering nonhuman animals as moral beings seems to arise from the recognition of traits in the animals similar to those in humans: the capacity to feel pleasure, pain and other emotions, the ability to reason and use language, and so on. Even if a good animal ethic is naturalistic and evolutionist and, therefore, able to identify the differences between humans and non-humans, the main goal must be to reduce the distance between the human and non-human world. With these observations in mind, I attempt to define the issues on which a dialogue between ethology and ethics could focus. I will concentrate on two specific issues. First, the concept of anthropomorphism; stressing differences and similarities between the ways this term is applied in ethology and in philosophical ethics. Second, welfare as a concept which bridges ethology and ethics (and is therefore open to both the risks and benefits of anthropomorphism), again stressing differences and similarities between its use by the two disciplines and suggesting what definitions might be common to them both.

\section{KARGER}

Fax +41613061234

E-Mail karger@karger.ch www.karger.com 
Session 1

\title{
The Chimpanzee, Pan troglodytes, as an 'Umbrella' Species for Conservation in Guinea-Bissau, West Africa: Opportunities and Constraints
}

\author{
Spartaco Gippoliti ${ }^{\text {, }}$ Claudia Sousa ${ }^{\mathrm{b}}$

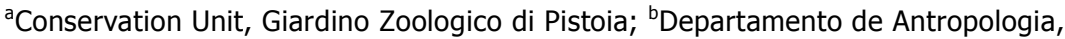 \\ FCSH, Universidade Nova de Lisboa, Lisboa \\ E-Mail spartacolobus@hotmail.com
}

Key Words: Chimpanzee - West Africa $\cdot$ Conservation - Sustainable development

Probably due to its small size, history and marginal geographic location, Guinea-Bissau has received scanty attention from primatologists and conservationists alike. As a result, the chimpanzee, Pan troglodytes, was, in 1988, officially reported to be extinct in the country. However, in 1994, a preliminary survey confirmed that the species still existed there, over most of its historic range. Urgent, active conservation measures were called for in the subhumid forests of the southwest. Eight years later, a conservation strategy for the West African chimpanzee was launched in the country. Because of the local cultural situation (it is taboo to hunt chimpanzees), Pan troglodytes is believed to coexist with humans over a large area south of the Corubal River. The situation of the chimpanzee populations north of the Corubal is unknown. A conservation strategy based only on the establishment of protected areas is not possible due to the growing, mainly rural, human population. At present, the ongoing community-based projects concerned with sustainable development seem to lack any critical test of whether they are achieving effective conservation of biodiversity in the country. Another challenge is to find a site for a long-term field study of the species; it must be suitable from both a conservation and a logistic point of view. The evaluation of the existing protected areas in terms of value for chimpanzee conservation is the first step in a national conservation strategy. While focusing on the chimpanzee as an 'umbrella' species, researchers and conservationists will attempt to collect information on the other primates and wildlife in Guinea-Bissau.

\section{Line Transects to Estimate the Abundance of Diurnal Primates in the Udzungwa Mountains National Park, Tanzania}

\author{
Francesco Rovero \\ Museo Tridentino di Scienze Naturali (Natural History Museum of Trento), Trento, Italy \\ E-Mail francesco_rovero@yahoo.it
}

Key Words: Censuses $\cdot$ Line-transects $\bullet$ Udzungwa Mountains

Procolobus gordonorum $\cdot$ Cercocebus sanjei

The Udzungwa Mountains of Tanzania $\left(10,000 \mathrm{~km}^{2}\right)$ contain the largest blocks of moist forest within the Eastern Arc Mountains, an area of global importance for conservation of biodiversity. These forests are especially rich in primates, containing at least 10 species of which 5 are diurnal, including the endangered and endemic Udzungwa red colobus (Procolobus gordonorum) and Sanje mangabey (Cercocebus sanjei). By undertaking census walks, we estimated the abundance of diurnal primates in the Udzungwa Mountains National Park $\left(2,000 \mathrm{~km}^{2}\right)$, in the northeastern portion of the mountain range. Fourteen replicates of three line-transects, each $4 \mathrm{~km}$-long, were walked over a period of seven months, with a total 
of $160 \mathrm{~km}$ censused. Transects crossed a variety of habitat types and altitudes, from lowland, dry woodland (300-500 m asl) to sub-montane, moist forest (500-800 m asl). Data on relative abundance (group sightings per km walked) show that red colobus was the most sighted species (0.46-0.69 groups per km walked), followed by black \& white colobus (Colobus angolensis, 0.35-0.50), Sykes' monkey (Cercopithecus mitis, 0.18-0.39) and yellow baboon (Papio cynocephalus, 0.02-0.13). The Sanje mangabey was the least sighted species, with a total of 7 group sightings scored during the whole period (0.02-0.06 groups per km walked). Absolute density, computed from data on sighting distances, was estimated for the red colobus only, for which comparable range-mapping data were also collected. Results of relative abundance and variations within and across transect lines are discussed in relation to gross habitat type and compared to those reported for primate communities from other forest sites in Africa. Methodological implications of applying line-transect techniques to estimate primate density in thickly forested and mountainous areas are also discussed.

\title{
Arboricolism Evolution of Western Red Colobus (Colobus badius temmincki) in the Forest of Fathala, National Park of the Saloum Delta, Senegal
}

\author{
Djibril Diouck \\ Université Cheikh Anta DIOP, Faculté des Sciences et Techniques \\ B.P. 5005 Dakar, Senegal \\ E-Mail djibrildiouck@hotmail.com
}

Key Words: Red colobus $\cdot$ Savanna $\cdot$ Arboricole $\cdot$ Semi-arboricole $\cdot$ Fathala $\cdot$ Senegal

The Fathal forest, in the National Park of the Saloum Delta in Senegal has, in the last 25 years, lost a considerable amount of its vegetation and its biodiversity. An earlier study on habitat use by western colobus (Colobus badius temmincki) showed that these monkeys were strictly arboreal, in spite of the dry habitat. This study shows the impact of habitat degradation on the behaviour of Colobus badius temmincki. Our observations related to two groups of monkeys which were followed from dawn to dusk from October 1994 - May 1995 (wet season) and during both wet and dry seasons in 1996. Scan samples were collected at 15 minute intervals, resulting in 7007 samples. The height of the trees and the position of the monkeys in the trees were estimated. The average height of Colobus badius temmincki in the trees was $5.7 \mathrm{~m}$, with a preference for the lower layers. The average height at which red colobus are observed has decreased significantly from 25 years ago ( $9 \mathrm{~m}$ in 1972). In addition, the monkeys were on the ground for $5 \%$ of the observation time during this study, while, according to Gatinot (1975), colobus used to be observed on the ground for only $0.1 \%$ of the time. Increased use of the ground is one of the adaptations developed by these monkeys. This adaptation allows $C$. $b$. temmincki to widen its ecological niche and to increase its survival chance in the savanna areas.

\section{The Population Density of Macaca sylvanus Is Not Responsi- ble for Damage to Cedar Forest in the Middle Atlas, Morocco}

\author{
Andrea Camperio Ciani, Loris Palentini, Maurizio Dell'Amico
}

Department of General Psychology, University of Padova, Italy

E-Mail andrea.camperio@unipd.it

Key Words: Bark stripping • Macaca sylvanus $・$ Morocco $・$ Population density

The aim of this study was to monitor changes in the population density of Barbary macaques (Macaca sylvanus) in relation to the quality of forest habitat and the presence of 
mixed flocks of goats and sheep in a large area of cedar forest in the Middle Atlas region of Morocco. The Moroccan Water and Forestry Department, suspecting the monkeys to be the main cause of damage to the cedars, has requested permission from IUCN to reduce the population of this primate in order to protect the forest. In fact, the authors suspect that some primates have already been removed from high-density areas (where there were 30-37 individuals per $\mathrm{km}^{2}$ ), particularly from those groups along roadsides. Based on the data collected in the region during the last 10 years (2805 $\mathrm{km}$ of the forest covered on foot), we suggest that the density of M. sylvanus is not responsible for forest degradation. The authors have observed that the bark stripping behaviour of the monkeys, considered by the authorities to be the main cause of harm to the forest, has declined in the last few years and, in fact, almost disappeared in most of the research areas. This seems to apply even to those areas where macaque density has remained unchanged, thus strengthening the hypothesis that the observed decrease in bark stripping is not correlated with the reduction in M. sylvanus numbers, but to ecological variables not directly related to this primate. At present, macaques still bark strip in those areas where the number of sheep and goats has increased and, as a result: i) access to water is impossible for the monkeys, due to the presence of permanent settlements around wells and ii) the vegetation in the area has deteriorated. In these areas, the greater incidence of bark stripping is a means of compensating for loss of minerals, nutrients and, especially, water. In areas invaded by Berber flocks, primate density has declined dramatically and yet deterioration of the forest due to bark stripping is most evident in these areas. This further supports the hypothesis that human factors, such as the growing impact of mixed flocks of goats and sheep grazing in the forest, the uncontrolled exploitation of the resources and the inappropriate political management of the forest, which are all altering the local ecology, are the main causes of the degradation, rather than primate density itself.

\title{
Session 2
}

\section{Food Sharing and Other Social Behaviours in Captive Bonobos}

\author{
Elisabetta Palagi ${ }^{\mathrm{a}, \mathrm{b}}$, Tommaso Paoli ${ }^{\mathrm{b}}$, Benedetta Balsotti ${ }^{\mathrm{b}}$, Silvana Borgognini Tarli ${ }^{\mathrm{b}}$ \\ ${ }^{a}$ Centro Interdipartimentale Museo di Storia Naturale e del Territorio, Univ. Pisa, via \\ Roma 79, Calci (Pisa), Italy; ' 'Dipartimento Etologia, Ecologia ed Evoluzione, Unità di \\ Antropologia, University Pisa, Italy \\ E-Mail nennirifh@yahoo.it
}

\section{Key Words: Food sharing $\cdot$ Reconciliation $\cdot$ Social bonds $\cdot$ Pan paniscus}

Bonobos, Pan paniscus, often share food in complex contexts and in conjunction with sexual behaviours. It may be that food sharing improves social relationships. This study analyses the connection of food sharing with social behaviours (grooming, sitting in contact and socio-sexual contacts) and the reconciliation process. The observations were carried out on the Apenheul (The Netherlands) bonobo colony, which was composed of 11 subjects at the beginning of the study. Since data collection occurred in three different phases, we used Matman 1.0 to ascertain the correlation among grooming and contact sitting matrices. We found a positive correlation that allowed us to use the three data sets together. We collected data using focal animal $(1313 \mathrm{~h})$, scan samples $(1048 \mathrm{~h})$ and all occurrences sampling methods. Via the last sampling method we collected 167 pairs of Post-Conflict and MatchControl observations. We found a significant positive correlation between food sharing, grooming, sitting in contact, and socio-sexual behaviours. Sequential analysis revealed no temporal association between socio-sexual contacts and food sharing. This finding does not seem to support the traditional paradigm of 'sex for food' in bonobos. Moreover, we found 
no difference in performing socio-sexual contacts before and after food sharing. Sociosexual interactions do not seem to be necessary prerequisites for food sharing, though they probably have a role in regulating social tension generated by food sharing. This study also reports findings on reconciliation in bonobos using controlled methods. The mean Conciliatory Tendency (CCT) value found in the Apenheul group was $24.8 \pm 41.3 \% \mathrm{SD}$. Our data also suggest that friendship (evaluated by contact sitting and grooming) positively affects the level of reconciliation, while close and weak relationships (evaluated by food sharing) do not affect reconciliation rates. In this study, dyads showing high frequency of food sharing did not necessarily show high levels of reconciliation.

\title{
Post-Conflict Third Party Affiliation in Captive Bonobos
}

\author{
Elisabetta Palagi ${ }^{\text {a, b }}$, Tommaso Paoli ${ }^{a}$, Benedetta Balsotti ${ }^{a}$, Silvana Borgognini Tarli ${ }^{a}$

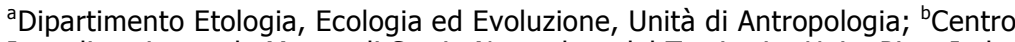 \\ Interdipartimentale Museo di Storia Naturale e del Territorio, Univ. Pisa, Italy \\ E-Mail t.paoli@deee.unipi.it
}

Key Words: Consolation • Triadic Contact Tendency $\cdot$ Socio-sexual behaviours $•$ Pan paniscus

Consolation describes an affiliative contact initiated by a third party and directed toward a victim of aggression. This behaviour seems to occur only in chimpanzees, Pan troglodytes and stumptailed macaques, Macaca arctoides. We collected 167 pairs of PostConflict and Match-Control observations (PC-MCs) in a captive group of bonobos, Pan paniscus, housed in Apeldoorn, The Netherlands, in order to investigate the occurrence of consolation and its functional role in this species. We found a significant difference in consolation between attracted and dispersed pairs, and the mean Triadic Contact Tendency (TCT) of all individual focals was $21.0 \% \pm 23.7 \%$ SD. Considering only adult focal subjects, the mean TCT was $20.6 \% \pm 19.4 \%$ SD. For subjects with at least $\mathrm{n}=5$ PC-MC pairs, the mean TCT was $14.0 \% \pm 30.3 \% \mathrm{SD}$. Consolation among adults varied greatly according to the sex of the victim: TCT for females as victims was $19.9 \% \pm 12.3 \% \mathrm{SD}$, and TCT for males as victims was $5.8 \% \pm 7.6 \% \mathrm{SD}$. Considering separately two groups of first affiliative contacts to console (affinitive and socio-sexual behaviours), we found that for socio-sexual contacts attracted pairs significantly overcame dispersed pairs, while for affinitive contacts we did not find any significant difference. The difference between mean TCTs related to these two groups of behaviours was statistically significant. In light of these findings, we can state that consolation is a complex phenomenon, the proximate and ultimate factors of which remain largely unknown. Though the Social Cognition and the Social Constraints Hypotheses might help us explain the mere presence of consolation in this group, the Tension Regulation Hypothesis can give us information about its possible adaptive value. In fact, the presence of a conflict can generate tension in the whole group and, as a consequence, a rapid escalation of aggressiveness: socio-sexual behaviours (a mechanism suitable for tension regulation in bonobos), that characterise the consolation process to a great extent, might be used to prevent the conflict spreading. Therefore, in our view, consolation seems to be a mechanism suitable for animals coping with the risk of social disruption resulting from aggression. 


\title{
Harassment and Social Instability in a Chimpanzee (Pan troglodytes) Colony: What Affects Rank Order and Inter-Individual Relationships?
}

\author{
Elisabetta Palagi ${ }^{\mathrm{a}, \mathrm{b}}$, Liliana Benedett $i^{\mathrm{b}}$, Silvana M. Borgognini Tarli ${ }^{\mathrm{b}}$ \\ ${ }^{a}$ Centro Interdipartimentale Museo di Storia Naturale e del Territorio, University Pisa, \\ Calci; 'bipartimento Etologia, Ecologia ed Evoluzione, Unità di Antropologia, University \\ Pisa, Italy \\ E-Mail lillabened@yahoo.it
}

\section{Key Words: Harassment $\cdot$ Social instability $\cdot$ Pan troglodytes $\cdot$ Rank order}

This study investigated the changes in rank order and in inter-individual relationships during a period in which mature females were harassed by young males. We observed the chimpanzee group at ZooParc de Beauval (St. Aignan Sur Cher, France) during October 2000-February 2001 (period 1) and October 2001-February 2002 (period 2). The colony was made up of 19 animals: 10 adults ( 2 males and 8 females), 4 juveniles ( 2 males and 2 females) and 5 infants. We employed the following sampling methods: focal-animal (period $1=824 \mathrm{~h}$; period $2=403 \mathrm{~h}$ ); scan samples (period $1=344 \mathrm{~h}$; period $2=351 \mathrm{~h}$ ) and all occurrences (period $1=412 \mathrm{~h}$; period $2=366 \mathrm{~h}$ ). We compared the data recorded in the second session (harassment period) with those from the first session (control period) using Matman's row-wise correlation tool for social interaction matrices. We employed only nonparametric tests to analyse data. We found a significant increase in agonistic contacts toward adult females by juvenile males with a consequent improvement in rank of the latter, thus confirming the rank improvement hypothesis previously formulated by other authors. The analysis of social interaction matrices (grooming, sitting in contact and play) of the two periods revealed a significant positive correlation. However, we found differences in the frequency distribution of sitting in contact and play: the former increased significantly in period 2 while the latter decreased. Grooming showed no difference in frequency distribution between the two periods. A further comparison was carried out on post-conflict behaviours: reconciliation, consolation and third-party affinitive contacts solicited by the victim. The reconciliation and consolation processes were not affected by the harassment period, while victims of aggressions solicited contacts by third-parties more frequently during that period. In conclusion, the harassment of adult females by juvenile males may induce changes at hierarchical level, but it does not seem to affect the affiliative relationship network among individuals.

\section{Conflict Management in Chimpanzees: The Role of Play Behaviour}

\author{
Elisabetta Palagi ${ }^{\mathrm{a}, \mathrm{b}}$, Giada Cordoni ${ }^{\mathrm{b}}$, Silvana M. Borgognini Tarli ${ }^{\mathrm{b}}$ \\ ${ }^{a}$ Centro Interdipartimentale Museo di Storia Naturale e del Territorio, Univ. Pisa, \\ via Roma 79, Calci (Pisa), Italy; ${ }^{b}$ Dipartimento Etologia, Ecologia ed Evoluzione, \\ Unità di Antropologia, Univ. Pisa, via S. Maria 55, Pisa, Italy \\ E-Mail giada.cordoni@tiscali.it
}

Key Words: Play $\cdot$ Social tension $\cdot$ Social tools $\cdot$ Conflict management $\cdot$ Pan troglodytes

Many authors agree that play behaviour occurs mainly when animals are free from environmental and physiological constraints. To test this hypothesis using controlled methods we investigated the occurrence of play during pre-feeding time, when a basic maintenance activity was going to take place. The study was carried out on the chimpanzee, Pan troglodytes, colony in the ZooParc de Beauval (St Aignan sur Cher, France). By scan sam- 
pling (344 h of observation), we recorded grooming and play interactions in all age-class combinations across four different periods (pre-feeding, feeding, post-feeding and control). During pre-feeding time, grooming among adults and play bouts between adults and unrelated immature subjects reached significantly higher levels than in any other period. These findings do not confirm the hypothesis mentioned above and suggest a possible role of grooming and play in conflict management. Like grooming, playful activity might alleviate the risk of aggressions, reducing social tension and increasing tolerance around the food (proximate benefit). Moreover, an adult might assess fairness of social bonds with other adults by playing with their immature relatives (social tools). Considering play among unrelated immature individuals, we again found a peak in frequency in the pre-feeding period. This activity might represent (especially for juveniles) a valid and safe mechanism for testing personal abilities (self-assessment), the skills of fellows and the degree of cooperation/ competition with them (social-assessment) during periods of high excitement. This new empirical evidence could reveal a role of play behaviour in conflict management, at least in chimpanzees.

\title{
The Introduction of a Juvenile Chimpanzee (Pan troglodytes) into a Group of Infant, Hand-Reared Chimpanzees
}

\author{
Francesca Ballo ${ }^{\mathrm{a}}$, Donata Grassi ${ }^{\mathrm{b}}$, Daniele Formenti ${ }^{\mathrm{a}}$, Cesare Avesani Zaborra ${ }^{\mathrm{b}}$ \\ ${ }^{a}$ Dipartimento di Biologia Animale, University Pavia; ${ }^{b}$ Parco Natura Viva - Garda \\ Zoological Park S.r.I., Bussolengo, Italy \\ E-Mail bulanlafra@hotmail.com
}

Key Words: Pan troglodytes $\cdot$ Introduction $・$ Socialisation $・$ Anomalous behaviour

The aim of this study was to describe changes in the behaviour of a group of four infant hand-reared chimpanzees (Pan troglodytes) when a hand-reared adolescent was introduced. The aim of the introduction was to reduce the abnormal behaviour of the adolescent and promote his socialisation. The study was carried out at the Parco Natura Viva (VR), from $1^{\text {st }}$ July 2002 to 28th February 2003. Data collection methods used were continuous recording (3940 min of observation) and focal-animal sampling. The results showed a significant reduction in abnormal behaviours $(\mathrm{p}<0.01)$ in the adolescent chimpanzee, with an increase in social play behaviour and a reduction in solitary play $(p<0.01)$. Some juvenile chimpanzees have been observed sucking their own toes. It is hypothesised that, in humans, this behaviour is due to being deprived of a mother. In our case, we hypothesise that this behaviour can have different causes, related to the individual showing it and to the context in which it takes place.

\section{Social Learning of Nut-Cracking Behaviour in Infant and Juvenile Chimpanzees (Pan troglodytes)}

\author{
Sarah Marshall-Pescini, Andrew Whiten
}

Scottish Primate Research Group, School of Psychology, University of St. Andrews, St. Andrews, UK

E-Mail sarahmarshallpescini@hotmail.com

Key Words: Social learning $•$ Chimpanzees $・$ Nut-cracking

Nut-cracking varies between communities of wild chimpanzees, both in its occurrence and in the tools used, in ways that suggest it is an example of 'cultural' behaviour. Detailed study of the acquisition of nut-cracking in wild chimpanzees is consistent with this conclu- 
sion. However, only one experiment has been carried out in captivity explicitly to test the role of social transmission in the acquisition of this behaviour, and this looked at adult chimpanzees. The study presented here is the first to investigate the effect of age and knowledgeable conspecific and human models on infant and juvenile chimpanzees' acquisition of nutcracking. Results confirmed that nut-cracking can be acquired by social learning, but only in chimpanzees 3 to 4 years old and above. Direct comparisons are made with a developmental study carried out on wild chimpanzees, revealing striking similarities.

\title{
Does Sexual Swelling Affect Post-Conflict Behaviour in Chimpanzee Females?
}

\author{
Elisabetta Palagi ${ }^{\mathrm{a}, \mathrm{b}}$, Rosarita Palomba ${ }^{\mathrm{b}}$, Silvana Borgognini Tarli ${ }^{\mathrm{b}}$ \\ ${ }^{a}$ Centro Interdipartimentale Museo di Storia Naturale e del Territorio, University Pisa,

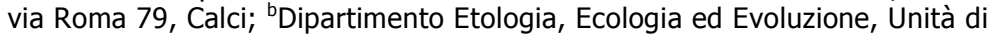 \\ Antropologia, Univ. Pisa, Via S. Maria 55, Pisa, Italy \\ E-Mail betta.palagi@museo.unipi.it
}

\section{Key Words: Sexual swelling $\cdot$ Reconciliation $\cdot$ Consolation $\cdot$ Pan troglodytes}

Many authors suggest that sexual swellings can induce not only physiological, but also behavioural changes in chimpanzee females. To test if the sexual swelling phase affects female post-conflict behaviour (reconciliation and consolation), we carried out a study on the chimpanzee, Pan troglodytes, colony in ZooParc de Beauval (St. Aignan sur Cher, France). The colony was made up of 19 animals: 2 adult males, 8 adult females and 9 immature subjects. We recorded all agonistic interactions that females engaged in with conspecifics by all occurrences sampling ( $778 \mathrm{~h}$ of observation). We collected a total of 284 Post-Conflict and Match-Control (PC-MC) pairs, following the subjects by focal animal sampling lasting $30 \mathrm{~min}$. The analysis of Conciliatory Tendency (CCT) and Triadic Contact Tendency (TCT) was carried out at the individual level. We gave females an oestrous condition score ranging from 0 (no swelling) to 2 (maximal swelling). In the case of reconciliation, we calculated CCT values as a function of the two different sexual periods: nonmaximum sexual swelling (0-1) and maximum sexual swelling (2). We did not find any significant difference between CCT levels in the two different phases considering both malefemale (M-F) and female-female (F-F) aggression: M-F, mean CCT (0-1) $=46.6 \% \pm 17.5$ $\mathrm{SD}$, mean CCT $(2)=0 \% \pm 29 \mathrm{SD}$; F-F, mean CCT $(0-1)=6.3 \% \pm 10 \mathrm{SD}$, mean CCT $(2)=$ $25 \% \pm 25 \mathrm{SD}$. Our results agree with those found in wild chimpanzees by Arnold and Whiten (2001): whether females did or did not experience oestrous, their condition did not affect the likelihood of reconciliation. Considering the first contact used to reconcile, females showed no significant difference between sexual and affinitive interactions in either period. Taking into account post-conflict behaviour involving third parties, we distinguished solicited and not solicited (consolation proper) contacts. TCT values did not show any significant difference in the two different sexual phases: mean solicited TCT $(0-1)=69.2 \% \pm 9.6 \mathrm{SD}$, mean solicited TCT $(2)=62.5 \% \pm 20.2 \mathrm{SD}$; mean consolation TCT $(0-1)=71.7 \% \pm 10.1 \mathrm{SD}$, mean consolation TCT $(2)=25 \% \pm 17.1 \mathrm{SD}$. Finally, our findings suggest that post-conflict mechanisms benefit females by repairing inter-individual relationships and maintaining group stability, independent of the sexual phase they experience. 


\title{
Tree Use by a Western Gorilla Group (Gorilla gorilla gorilla) in the Dzanga-Ndoki National Park, Central African Republic
}

\author{
Shelly Masi \\ Università degli Studi di Roma 'La Sapienza', Dipartimento di Biologia Animale e \\ dell'Uomo, Piazzale Aldo Moro ${ }^{\circ}{ }^{\circ}$, Rome, Italy \\ E-Mail astraterza@tiscali.it
}

Key Words: Tree use $・$ Body size $・$ Frugivory $・$ Western gorillas

Field research was conducted on an habituated western gorilla group (Gorilla gorilla gorilla) at the Bai-Hokou study site, Dzanga-Ndoki National Park, Central African Republic from December 2000 to November 2001. The group was composed of a silverback, an adult female and a juvenile. The aim of this study was to examine tree use and the effect of body size; gorillas are among the most sexually dimorphic of any primate species. In contrast to the abundant data available on mountain gorilla (Gorilla beringei beringei) behaviour, little is known about the habits of western gorillas. This is the first study of the arboreal behaviour and activities of habituated members of this subspecies. The adults used trees mainly to feed in, whereas the juvenile also used trees to play in. Contrary to traditional expectations about the relationship of large size to arboreal behaviour, results of this study showed that all size classes of gorillas, even the silverback, regularly used arboreal substrates. However, this study confirmed the hypothesis that differences in body size are associated with differences in substrate use. On the basis of body size, larger individuals are expected to climb trees less often, and, in fact, in this study the most arboreal was the juvenile and the least was the silverback. Moreover, it was found that the juvenile and the female climbed more frequently in the months when they fed on a greater quantity of fruit. The silverback, in contrast, although consistently the least arboreal of the group, was observed climbing more often in the months when less fruit was eaten. Considering the juvenile separately, different tree use by the sexes did not correspond to a sex difference in the diet. This could be ascribed to the male's privileged access to the fruit on the ground whereas the female, less constrained by body size, could directly harvest fruit on the tree.

\section{Session 3}

\section{Animal Welfare and Enrichment: a Preference Study in the Common Marmoset (Callithrix jacchus)}

\author{
Arianna Manciocco, Maria Puopolo, Augusto Vitale \\ Department of Cell Biology and Neuroscience, Istituto Superiore di Sanità, Rome \\ E-Mail6gatti@libero.it
}

Key Words: Animal welfare $\cdot$ Callithrix jacchus Environmental enrichment

The aim of this work is to verify the effectiveness of an environmental enrichment technique based on the concepts of choice and control by the animals involved. We consider the methodology applied in this study more effective in improving the welfare of laboratory animals, compared to the imposition of a particular enrichment by the researcher. Another important concept underlining the present work is that the captive animals should show a behavioural repertoire as close as possible to the repertoire shown in the natural environment. Two kinds of enrichment have been presented to a colony of common marmosets (Callithrix jacchus) housed at the Istituto Superiore di Sanità in Rome. One type 
of enrichment was related to the physical environment, i.e to furnishing of the cage; the other related to feeding behaviours. For the former, three families of common marmosets were presented with three pairs of enrichments: i) wooden platforms vs. wooden shelters; ii) fixed branches vs. moving branches; iii) high branches vs. medium-high branches. The enrichments were chosen on the basis of the ecoethological characteristics of the species under study. Within each pair, the monkeys could choose which situation to exploit more. Concerning feeding behaviours, the choice consisted of the food prepared as usual in our laboratory, that is, fruit cut in pieces and presented in an open dish, and the fruit inserted as a whole in a pointed branch. Furthermore, both a familiar and a novel fruit were presented in the two modalities in order to study the effect of novelty. With regard to the choice of physical environments, the monkeys did not show any significant choice, although non-significant tendencies were observed. For instance, one family preferred the shelters, rather than the platforms, for resting and engaging in social activities. In the case of the foraging activities, contrary to what we expected, the marmosets showed a significant preference for exploring and consuming the familiar food presented in the familiar way. However, a considerable variability between and within families was observed. In general, the results showed that the monkeys choose much less than expected. Such lack of choice could be interpreted on the basis that the actual housing situation of our monkeys corresponds to an acceptable level of welfare: the marmosets do not have enough motivation to express a particular choice for a particular environmental situation. Such results suggest that, among the factors to be taken into consideration when choosing a particular enrichment, it is important to consider the housing history of that particular colony. Furthermore, the behavioural variability existing between and within families can have, as a possible consequence, the differential use of a particular enrichment.

\title{
Response to a Manual Task by the Common Marmoset (Callithrix jacchus)
}

\author{
Emanuele Licata, Amanda Tedesco, Maria Puopolo, Augusto Vitale \\ Department of Cell Biology and Neuroscience, Istituto Superiore di Sanità, Rome \\ E-Mail vitale@iss.it
}

\section{Key Words: Callithrix jacchus $・$ Manual task $・$ Problem solving}

The aim of this work was to study the reaction of captive common marmosets (Callithrix jacchus) to three different manual tasks. The equipment and tasks consisted of: i) a transparent box with a movable top, to be shifted horizontally; ii) a transparent rotating cylinder, to be vertically rotated by $360^{\circ}$; iii) a transparent fixed cylinder, with a Perspex sheet near the top, to be pushed or pulled in order to release a piece of food into the bottom of the cylinder. All three pieces of equipment contained a small piece of a preferred food item. The three tasks, although different, shared the characteristic that just one motor action was required to solve them. The experimental subjects were seven adult marmosets, each one tested alone. Each individual received three presentations of each of the three tasks. The behaviours considered were: number of solutions; time spent near the equipment; latency to reach the equipment; time spent in trying to solve the tasks. Four individuals out of seven solved the tasks, with one subject solving all of the tasks in all of the presentations, but the type of task did not influence the frequency of solution. In other words, the level of complexity of the three tasks appeared to be similar. Individual styles were evident in the solution observed. However, the marmosets appeared to be less interested in the rotating cylinder than in the other two pieces of equipment. In fact, the frequency and duration of attempts to solve the task involving the rotating cylinder were significantly lower than for the box and the fixed cylinder tasks. Solvers and nonsolvers did not differ in the level of attention dedicated to the tasks. Furthermore, none of the behavioural parameters considered changed across presentations. The results show that these kinds of tasks can be solved by the common marmoset, without active teaching by the experimenter or social facilitation, but simply by trial and error. Such ability did not seem to be simply progressively learned by an increasing and constant level of attention toward the tasks, since the behaviour of solvers and non-solvers did not statistically differ in frequency and duration. The possibility of insightful learning in common marmosets, influenced by individual differences in temperament, could be one of the reasons for the different degree of ability showed by different individuals. 


\title{
The Role of Individual Learning, Social Facilitation and Stimulus Enhancement in the Acquisition of an Object-Choice Task in Tufted Capuchin Monkeys (Cebus apella)
}

\author{
Elsa Addessi, Elisabetta Visalberghi \\ Istituto di Scienze e Tecnologie della Cognizione, Consiglio Nazionale delle Ricerche, \\ Roma, Italy \\ E-Mail elsa_addessi@yahoo.it
}

Key Words: Cebus apella • Individual Learning • Stimulus enhancement • Social facilitation

A group member's activities might provide relevant information about its environment to a naïve individual. The social learning mechanisms involved are cognitively less demanding than imitation. Social facilitation is the increased probability of performing a behaviour already present in the species' repertoire when a conspecific is performing the same behaviour. Stimulus enhancement occurs when a demonstrator's activities make more salient a particular aspect of the stimulus to which the response has to be given. The likelihood of an observer interacting with that stimulus is, therefore, increased. Our previous studies on tufted capuchins showed that, although novel food acceptance is enhanced by social influences, the observers are not directed to a specific food target. The present experiment investigated the relative contribution of individual learning, social facilitation and stimulus enhancement to the acquisition of an object-choice task in tufted capuchin monkeys. We used an observer-demonstrator paradigm, in which a naïve individual (observer) and an experienced group member (demonstrator) were in nearby cages and could see each other through a Plexiglas window. There were three experimental conditions: (1) Demonstration only: both the observer and the demonstrator faced a choice between two plastic bricks differing only in colour; the demonstrator had previously been trained to manipulate a brick of only one colour (yellow or blue, depending on the experimental group), without obtaining a reward, (2) Demonstration plus reward: both the observer and the demonstrator faced a choice between two plastic bricks differing only in colour; the demonstrator had previously been trained to manipulate a brick of only one colour in order to obtain a food reward, and (3) No demonstration: the observer faced a choice between two plastic bricks differing only in colour; the demonstrator was present but without having plastic bricks available itself.

\section{Within-Group Variability in Foraging among Tufted Capuchins (Cebus apella) in Iguazú National Park, Argentina}

\author{
Ilaria Agostini, Elisabetta Visalberghi \\ Istituto di Scienze e Tecnologie della Cognizione, Consiglio Nazionale delle Ricerche, \\ Rome, Italy \\ E-Mail ilaria_agostini@hotmail.com
}

Key Words: Foraging patterns $\cdot$ Proximity $\cdot$ Juveniles $\cdot$ Tufted capuchins $\cdot$ Cebus apella

Recently, great attention has been paid to traditions (Fragaszy \& Perry 2003) in several animal species including wild Cebus capucinus. Evaluating the evidence for such a phenomenon requires a deep understanding of intra-population behavioural variability, whether due to asocial or social factors. The variability of foraging patterns and spatial patterns across age and sex classes was studied in a group of 38 tufted capuchin monkeys (Cebus apella) for a period of 9 months. The capuchins were living in humid subtropical forest in Iguazú National Park, Argentina. Foraging variability was analysed in terms of proportions of focal samples devoted to foraging on certain targets, substrates, supports, food processing 
techniques and effectiveness. Spatial associations among individuals were assessed for neighbours within distances of 5 metres. Statistical analyses indicate that sex differences in foraging behaviour are pronounced and seem to override age differences. Overall, males are more efficient foragers than females. They eat more animal foods, forage for invertebrates on woody substrates, forage on trunks, the ground and low supports and perform more 'pounding' behaviour than females. Females eat more fruits and forage more on bamboo substrates and small supports than do males. Juveniles are similar to the same-sex adults for food targets, foraging substrates and support choice, but are less efficient than adults. Overall, these results confirm those of Fragaszy (1986) for Cebus olivaceus. Finally, since proximity patterns indicate that juveniles of each sex stay in close spatial association with samesex elders, the finding that juveniles acquire the foraging patterns typical of their sex could be attributed either to social factors or to sex-specific traits.

\title{
Session 4
}

\section{The Use of Landmarks for Spatial Representation by Capuchins (Cebus apella)}

\author{
Paola Bartolommei ${ }^{\mathrm{a}, \mathrm{b}}$, Patrizia Poti ${ }^{\mathrm{a}}$

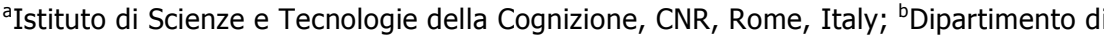 \\ Biologia Animale e dell'Uomo, University 'La Sapienza', Rome, Italy \\ E-Mail paolabartolommei@libero.it
}

\section{Key Words: Landmarks $\cdot$ Spatial representation $•$ Capuchins}

We aimed to evaluate, in controlled conditions, how capuchins use environmental landmarks to find the location of a food reward. In the first experiment, a capuchin learned to find a hidden reward in one of many identical containers placed on a platform. The reward was always in the container at the centre of four red cylinders, used as landmarks, always in the same configuration. The landmark configuration was shifted around the platform on each trial, to train the animal to base its search on the landmarks. When the subject learned to find the reward at the first attempt, we doubled the distances between the landmarks, thus expanding the landmark configuration. If the animal used the landmarks in a configurational way, that is putting them in relationship to one other, during the trials with the expanded configuration it would have continued to look for food at the centre of the landmark configuration since the change in scale did not affect the relative distance between the objective and the landmarks. If, however, the animal used the landmarks independently one from the other, it would have searched near each landmark or in the containers that were placed at the same distance and direction as in the training trials. In the trials with the expanded configuration, the subject mainly searched in the containers near two of the four landmarks. We therefore carried out a second experiment using a configuration of only two landmarks. In this case we wanted to verify whether, in a simpler situation, the capuchins were able to learn the existing relationship between two landmarks and to evaluate whether they were able to calculate the exact distance between the reward and each landmark, even without using the configuration. Two capuchins were used in this experiment. In the trials with the expanded configuration, both the subjects searched for the food mainly in the two containers placed between the landmarks, the distance between each one being equal to the distance which had been learned during the training trials. These results show that capuchins do not use environmental references in a configurational way but use them independently one from the other as separate sources of information. Furthermore, capuchins are able to evaluate the exact distance of the reward from each individual landmark. 


\title{
A Comparative Analysis of Perceptual Grouping Processes in Humans (Homo sapiens) and Tufted Capuchin Monkeys (Cebus apella)
}

\author{
Giovanna Spinozzi ${ }^{\mathrm{a}}$, Carlo De Lillob ${ }^{\mathrm{b}}$ Sara Castellia \\ ${ }^{a}$ Istituto di Scienze e Tecnologie della Cognizione, C.N.R., Unità di Primatologia \\ Cognitiva e Centro Primati, Roma, Italia; ${ }^{b}$ Department of Psychology, University of \\ Leicester, Leicester, UK \\ E-Mail spinozzi@pml.it
}

\section{Key Words: Part-whole perception • Embedded figures $\cdot$ Homo sapiens $\cdot$ Cebus apella}

Perceptual grouping is the ability to integrate the information that reaches sensory receptors into global representations and has been extensively investigated in human cognition where most research is focused on the mechanisms allowing our perceptual system to segment an entity into its constituent parts and to integrate these parts into a coherent whole. In the present study, we carried out a comparative investigation of perceptual grouping processes in 128 humans (Homo sapiens), and six tufted capuchin monkeys (Cebus apella), using simultaneous matching-to-sample versions of two complementary types of embeddedfigures tasks, both requiring the subjects to judge whether one pattern was part of another or not. In the first task (Task 1), subjects received a complex pattern as the sample and had to choose which one of the two comparison stimuli featured a part of the sample. In the second task (Task 2), the sample featured the stimulus parts and the comparison stimuli the complex pattern; here, the subjects had to identify which of the comparison stimuli included the sample. The analysis of capuchins' accuracy scores showed that, in Task 1, the monkeys found it easier to identify the parts of the complex stimuli when these parts were a set of ungrouped elements than when they formed grouped units. This was true irrespective of whether the complex patterns were organised as closed (e.g. three overlapping squares) or open (e.g. three overlapping crosses) shapes. In Task 2, the performance level of the monkeys for ungrouped elements was indistinguishable from that observed for grouped parts. A different pattern of results emerged from the analysis of data collected with human participants. In contrast to the monkeys, the accuracy of humans was higher for grouped than for ungrouped parts. Moreover, unlike monkeys, humans were always better at processing closed shapes. Overall, these findings suggest that humans and non-human primates use different perceptual strategies for the analysis of multi-component patterns.

\section{The Importance of Spatial Organisation of Parts for Visual Stimulus Recognition in Capuchin Monkeys (Cebus apella)}

\author{
Valentina Truppa ${ }^{a}$, Giovanna Spinozzi ${ }^{\mathrm{a}}$, Carlo De Lillo ${ }^{\mathrm{b}}$ \\ ${ }^{a}$ Istituto di Scienze e Tecnologie della Cognizione, Consiglio Nazionale delle Ricerche, \\ Rome, Italy; 'bepartment of Psychology, University of Leicester, UK \\ E-Mail spinozzi@pml.it
}

Key Words: Perceptual organisation • Picture recognition • Part-whole relationship • Cebus apella

Biederman (1987) proposed that object recognition relies on structural descriptions that specify which parts belong to a particular object and their spatial relationship. We carried out two experiments aimed at assessing the extent to which the preservation of the spatial relationship between component parts of visual patterns facilitates the identification of complex patterns by tufted capuchin monkeys (Cebus apella). All experiments were based on a simultaneous matching-to-sample (MTS) task. In Experiment 1, six adult tufted capuchins 
were initially trained to discriminate three complex visual stimuli using an identity matching to sample. The testing phase that followed featured a similarity MTS where the monkeys were presented with the stimuli used in the training phase as the sample and modified versions of them as the comparison stimuli. Different experimental conditions featured comparison stimuli obtained by performing: 1) the global rotation of the stimuli; or 2) the independent rotation of different component parts of the stimuli; 3 ) the spatial translation of the component parts of the stimuli; or 4) the simultaneous rotation and translations of the parts of the stimuli. Identity MTS trials were interspersed with trials featuring the above conditions to ensure that a satisfactory MTS level of performance was maintained during the testing phase. Capuchins' discriminative performance was not affected by global rotations of the stimuli but was disrupted by all the other manipulations involving a disruption of the spatial relationship between the component parts of the stimuli. In Experiment 2, we used a similar procedure. However, only single component parts of the stimuli were manipulated and presented as comparison stimuli. In some trials, the single parts remained in the original position as they appeared in the sample, while in other trials, their original position and/or orientation was manipulated. Capuchins' discriminative performance was highly accurate in all conditions of the experiment. Overall, these findings suggest that capuchins' pattern recognition processes take into account both the local characteristics of complex stimuli and their spatial organisation. Nevertheless, the recognition of a single part of a visual stimulus in this species is not disrupted by manipulations affecting its spatial displacement or rotation.

\title{
A New Technique for the Study of Facial Expressions in Non-Human Primates
}

\author{
Marco Maria Rigamonti
}

Centro di Primatologia HSR, Milan, Italy

E-Mail marco.rigamonti@hsr.it

\section{Key Words: Laterality $・$ Facial expression $・$ Macaca nemestrina $\bullet$ Emotions}

Facial expressions in non-human primates are of great interest when studying communication, emotion, cognitive functions, lateralised behaviours and social relations. Complex methodological problems, however, must be faced if one tries to measure this behaviour finely. For this research, we constructed an apparatus specifically designed to study facial expressions in pig-tailed macaques (Macaca nemestrina). We trained 20 subjects to climb in the apparatus in which rewards could be administered. In addition, pictures or movies were presented on a computer monitor. A video camera was placed frontally at a short distance from the subject. A lighting system was built to light the face of the monkey uniformly. A second video camera was placed over the top to monitor the position of the subject with respect to the apparatus. Using this technique, we recorded digital movies that were analysed frame by frame. Results were obtained for dynamic motor patterns of facial expressions and asymmetry of the face. Every element of the face (e.g.: eyebrows, lips, ears) was identified and analysed separately in several facial expressions. The role of each component varied in different situations and in different facial expressions. Additionally, we obtained individual patterns of asymmetry in the face at rest. 


\title{
Study of Hand Preference in Barbary Macaques (Macaca sylvanus)
}

\author{
Eugenia Zandonà ${ }^{a}$, Marco Maria Rigamonti ${ }^{\mathrm{b}}$, Donata Grassi ${ }^{\mathrm{a}}$, Cesare Avesani ${ }^{\mathrm{a}}$, \\ Laura Guidolin ${ }^{\text {a }}$ \\ ${ }^{a}$ Dipartimento di Biologia, Univ. of Padova, ${ }^{b}$ Centro di Primatologia HSR, Milano; \\ 'Parco Natura Viva - Garda Zoological Park, Bussolengo, Italy \\ E-Mail marco.rigamonti@hsr.it
}

\section{Key Words: Laterality • Handedness • Macaca sylvanus}

Fifteen years after the publication of the paper by McNeilage, Studdert-Kennedy and Lindblom (1987) that gave rise to the debate on hand preference in non-human primates, the results of experiments are still subject to various and discordant interpretations. On one hand, there are still many differences in the methodological approaches used, on the other, the experimental context in which observations are carried out seems to be an important variable. Moreover, there are many species for which experimental data are not yet available. In this study, we present new data on hand preference in Barbary macaques (Macaca sylvanus), a species still unknown in this perspective. We observed 15 semi-free ranging macaques at Parco Natura Viva - Garda Zoological Park. Data were recorded for five behavioural categories observed during feeding, locomotion and social interaction. Two-tailed, non-parametric statistical tests were run to analyse data. Our results seem to offer a perspective that is concordant with most studies carried out with other species of the genus Macaca. Moreover these results suggest that, for this kind of research, some behavioural categories, those more similar to the ones observed in nature, are better than others.

\section{Session 5}

\section{Feeding Eco-Ethology of Propithecus verreauxi verreauxi in Kirindy Forest, Western Madagascar: Results of Observational, Ecological and Ethnobotanical Data}

\author{
Ivan Norscia, Valentina Carrai, Silvana M. Borgognini Tarli \\ Dipartimento di Etologia, Ecologia ed Evoluzione, Unità di Antropologia, Pisa, Italy \\ E-Mail borgognini@discau.unipi.it
}

Key Words: Eco-ethology • Madagascar $・$ Propithecus verreauxi $\bullet$ Feeding behaviour • Ethnobotany

Propithecus verreauxi verreauxi, Verreaux's sifaka, is a diurnal, vegetarian and almost completely arboreal lemur, which lives in groups of 4-8 individuals. It can be found in both wet and dry Malagasy forests, and it has been extensively studied in southern sites. The subject of this study was the feeding eco-ethology of P.v.verreauxi. The lemurs were studied in a dry deciduous forest in western Madagascar (Kirindy, Morondava) during the central part of the dry season (June-September 2001). Data were collected by focal animal sampling from 12 individuals, three per group (one male and two females). Each group was followed for three consecutive days per month, changing the focal subject every sixty minutes, in order to collect one complete day of observation per subject per month. Daily observations covered the animals' whole activity period (from morning wake-up to evening final rest). Each plant eaten was marked, mapped and identified. Temperature and humidity were re- 
corded daily. Ground samples and a census of the sifakas' favourite plant species were taken along transects laid down through the whole study area. An ethnobotanical survey on the plant species eaten by the sifakas during the observation period was also performed. Our results show that sifakas spend most of their activity time resting and feeding. They switched from leaves to flowers depending on the phenological fluctuations of the vegetation in the forest and exploited all three levels of the forest (higher, intermediate and lower). The two main criteria used by sifakas in selecting food appeared to be: variety (of the type of resource eaten) and selection (independent of the abundance of the species eaten). The time budget and the main ecological correlates analysed (humidity, temperature and soil conditions) revealed that the dry season might not be as stressful for sifakas as previously suggested. Feeding time varied among groups and between females and males, possibly depending on food availability in the home range of each group and on feeding priority granted to females. Feeding choice and licking activity also differed between pregnant/ lactating and non-reproductive females. Finally, preliminary ethnobotanical results seem to suggest that the sifakas' food choice might be, at least in part, conditioned by some medical properties of the plants eaten.

\title{
Male Scent-Marking in Lemur catta: An Investigation by Chemical and Behavioural Approachs
}

\author{
Stefano Vaglio , Elisabetta Palagi ${ }^{\mathrm{a}, \mathrm{b}}$, Sabrina Telara ${ }^{\mathrm{a}}$, Francesca Boscaroc, \\ Gloriano Moneti ${ }^{c}$, Silvana Borgognini Tarli ${ }^{\mathrm{a}}$ \\ ${ }^{a}$ Dipartimento di Etologia, Ecologia ed Evoluzione, Unità di Antropologia, Univ. of Pisa; \\ ${ }^{b}$ Centro Interdipartimentale Museo di Storia Naturale e del Territorio, Univ. of Pisa; \\ ${ }^{c}$ Centro Interdipartimentale di Spettrometria di Massa, Univ. of Florence, Italy \\ E-Mail pasticcere@yahoo.com
}

Key Words: Scent-marking $\cdot$ Chemical investigation $\cdot$ Behavioural approach $•$ Lemur catta $\cdot$ Olfactory communication

Lemur catta shows a complex system of olfactory communication that plays a crucial role in both inter-group territorial defence and in intra-group social relations. Both females and males mark the substrate with their genital glands; males can also deposit secretions with ante-brachial organs (wrist mark) and brachial organs (wrist to pit). Males also perform tail-anointing and tail-waving towards other males (stink fights) and towards females (courtship). The aim of this study was to investigate olfactory communication using both chemical and behavioural approachs. The research was carried out on the group of Lemur catta housed at Pistoia Zoo (Tuscany, Italy). Using all occurrence sampling, we observed all olfactory behaviour for $196 \mathrm{~h}$ from October 2002 to February 2003. To collect the olfactory secretions, we placed filter paper on special supports and the lemurs marked these spontaneously. The analysis of non-volatile compounds was carried out by gel-electrophoresis and by protein sequence procedures, while volatile compounds were analysed by gaschromatography-mass spectrometry. Results show that secretions contain an unknown glycosilated protein (analogous to the lipocaline family found in non-primate mammals) with a high affinity to bind volatile molecules. The protein was found only in male scent-marks, particularly when brachial secretions were mixed with ante-brachial ones (wrist to pit + wrist mark). Squalene and some of its isomers have been found to be the main components of the volatile compounds. All these compounds were present in the secretions released both by wrist to pit + wrist mark and by wrist mark. A preliminary analysis shows the occurrence of different proportions of the squalene isomers in the samples from each animal. Preliminary chemical investigation suggests that the glycosilated protein binds the squalene in wrist to pit + wrist mark secretion. Moreover, behavioural observations show that wrist to pit is strictly related 
to wrist mark (non-volatile + volatile compounds), while it is not related to the tail-anointing and tail-waving, two types of marking characterised by immediateness, directionality and rapid diffusion.

\title{
Faecal Steroids as Indicators of Reproductive Status and Animal Welfare in Lemur catta
}

\author{
Claudia Carraro a , Donata Grassi ${ }^{\mathrm{b}}$, Alessandra Broli ${ }^{\mathrm{c}}$, Claudia Simontacchi ${ }^{\mathrm{a}}$ \\ a Dipartimento di Scienze Sperimentali Veterinarie, Facoltà di Medicina Veterinaria, \\ Univ. of Padova; ' Parco Natura Viva - Garda Zoological Park, Bussolengo; 'Univ. of \\ Parma, Italy \\ E-Mail carraro.claudia@libero.it
}

\section{Key Words: Lemur catta $\cdot$ Faecal steroids $\cdot$ Stress $・$ Reproductive status}

The determination of the reproductive status (gonadal activity) and the physiological well-being (adrenocortical activity) of animals in captivity is one of the most important factors for effective management. Recently, non-invasive techniques, such as faecal steroid analysis, have been developed for monitoring the endocrine status in non-human primates. These methods are of great importance because they avoid additional stress from, for instance, catching, constraining and manipulating the animals. The aim of this study was both to validate a method for measuring faecal steroid levels and to monitor the reproductive conditions and welfare of ring-tailed lemurs (Lemur catta) housed at Parco Natura Viva, Italy. The group consisted of 3 males (1 adult and 2 young) and 7 females (4 adults and 3 young) with their offspring. We collected fresh faecal samples during two different periods (February-March 2002 and April-July 2003). During sampling, the females were in different reproductive conditions: pregnant, post-partum, cycling, puberty or pre-puberty. Faecal samples were collected every 3 days, always in the morning, and immediately frozen at $-20^{\circ} \mathrm{C}$. Progesterone, oestradiol, testosterone and cortisol were detected in faeces by a validated microplate radioimmunoassay (RIA). To extract steroids from faeces, we used diethyl ether. This extraction method has been validated by dilution, recovery and precision tests both for sexual steroids and glucocorticoids. The low and constant faecal cortisol levels found in males and females indicated the absence of stressful conditions and seemed to confirm that the lemurs were well adapted to captivity. In contrast to other authors, we did not find an increase in cortisol levels in late pregnancy and post-partum. Faecal progesterone analysis has been successfully used for monitoring pregnancy in this species. In particular, we found higher progesterone levels during pregnancy, followed by a significant decrease before delivery and lower levels during post-partum. Progesterone analysis is also useful for monitoring the reproductive cycle in that, in two cyclic females, we found progesterone peaks correlated with the luteal phase. In contrast, faecal oestrogen levels were not reliable indicators of reproductive status as reported in other studies. Finally, we found higher faecal testosterone levels in the adult male than in the young males indicating that it may be possible to use this analysis to monitor male sexual maturity. 


\title{
The Role of Phytochemistry in the Food Choice of a Malagasy Prosimian, Eulemur collaris
}

\author{
Giuseppe Donati, ${ }^{\mathrm{a}}$, An Bollen ${ }^{\mathrm{b}, \mathrm{c}}$, Nicoletta Baldi ${ }^{\mathrm{a}}$, Silvana M. Borgognini Tarli ${ }^{\mathrm{a}}$ \\ ${ }^{a}$ Department of Ethology, Ecology and Evolution, Unit of Anthropology, University of \\ Pisa, Italy; 'nstitute of Zoology, Unit of Ecology and Conservation, University of \\ Hamburg, Germany; 'Department of Biology, University of Antwerp, Belgium \\ E-Mail gdonati@deee.unipi.it
}

\section{Key Words: Nutritional ecology $\cdot$ Food choice $・$ Madagascar $・$ Littoral forest $・$ Eulemur collaris}

In the last two decades, nutritional ecology has been found to be fundamental for fully understanding the behavioral ecology of primates in the field. The aim of this work was to describe the role of phytochemistry in determining the food choice of the collared lemur, Eulemur collaris. Data on feeding ecology were obtained through systematic observations of two habituated groups of this frugivorous lemur from December 1999 through January 2001. Samples of each food item were collected, dried and subsequently analysed for their lipid, protein (total and soluble proteins), carbohydrate, fibre (ADF, NDF) and tannin content. Water content was estimated by the difference between fresh and dry weight and the caloric yield was calculated indirectly. Based on feeding time, food samples were categorised in non-eaten, marginal, minor and preferred food items as well as in the classes diurnal and nocturnal depending on the time when they were mostly consumed. We noted a dietary preference towards fruits with an high water content and a low fat content. When distinguishing between marginal, minor and preferred food items no important differences could be observed, even though, surprisingly, the carbohydrate content was significantly lower in preferred fruits compared to the marginal ones. Fruits eaten during the day contained a significantly higher carbohydrate content and a lower, but not significant, fibre content compared to fruits consumed at night. Overall, collared lemurs did not show clear evidence for fruit selection based on specific nutrients, but rather an opportunistic dietary strategy dictated by overall fruit availability. Nevertheless, a selection towards high quality food during the diurnal phase of their 24-hour activity did stand out.

\section{Session 6}

\section{Fundamental Frequency Variation in the Vocal Repertoire of Ruffed Lemurs (Varecia variegata)}

\author{
Marco Gamba, Cristina Giacoma \\ Dipartimento di Biologia Animale e dell'Uomo, Via Accademia Albertina 17, \\ I-10134 Turin, Italy \\ E-Mail marco.gamba@unito.it
}

Key Words: Lemurs $・$ Vocalisations $\cdot$ Chaotic patterns $・$ Acoustics $・$ Communication

During social interactions, vocal emissions are used to express a variety of information and often receivers assess emitter's characteristics using the information conveyed in communication signals. In many species, the fundamental frequency of acoustic signals plays an important role in the communication system, and it is possible to discriminate between signals that differ in fundamental frequency. This has been investigated in ruffed lemurs 
(Varecia variegata) in the present study. We found evidence that different species-typical vocal types can be discriminated by variation in fundamental frequency as well as by fundamental frequency itself. Looking at data analysed using the Kruskal-Wallis test ( $\mathrm{n}=55, \mathrm{t}=$ 19.269 , df $=3$ ), we find a $\mathrm{p}$ value of $<0.0001$. We conclude that fundamental frequency values differ markedly across the four groups of vocal types we considered (mews, chatters, alarm calls, growls). These vocal types also showed different patterns of variation, statistically significant results were found examining average individual coefficients of variation (CVs) by ANOVA: mews and growls showing lower CVs both in duration $(\mathrm{n}=55, \mathrm{R}=$ $0.489, \mathrm{df}=3, \mathrm{p}=0.003)$ and in fundamental modulation $(\mathrm{n}=55, \mathrm{R}=0.485, \mathrm{df}=3, \mathrm{p}<$ $0.001)$ and chatters and alarm calls showing higher rates. We investigated correlation between vocal type fundamental variation and occurrence of non-linear phenomena (subharmonics, chaotic patterns). We found that alarm calls and chatters show the highest rate in fundamental frequency variation (respectively $0.374 \pm 0.246,0.527 \pm 0.386$ ) and are very often characterised by non-linear phenomena. We classify alarm calls and chatters as urgency related vocal signals and consider their higher rate in fundamental frequency variation as a consequence of the signaller's perception of urgency. However, we suggest that higher variation in fundamental frequency can encode itself as communicative meaning.

\title{
Semantic Content in the Alarm Calls of Black and White Colobus (Colobus polykomos polykomos)
}

\author{
Sandra Tranquilli ${ }^{\mathrm{a}, \mathrm{c}}$, Klaus Zuberbuhler ${ }^{\mathrm{b}, \mathrm{c}}$ \\ a'Dipartimento di Biologia Animale e dell'Uomo - University 'La Sapienza', Rome, Italy; \\ bepartment of Psychology, University of St Andrews, Scotland, UK; 'Centre Suisse de \\ Recherches Scientifiques, Tai Monkey Project, Abidjan, Ivory Coast \\ E-Mail satranq@tin.it
}

Key Words: Predation • Alarm calls • Semantic content $•$ Colobus monkeys

Most evidence for predator-specific alarm calls in non-human primates comes from a small number of species, mainly guenons (Cercopithecus spp.), questioning whether semantic communication is a general feature of non-human primate communication. To address this issue, we conducted a study on alarm call behaviour of black-and-white colobus, Colobus polykomos polykomos, in the Tai forest, Ivory Coast. These monkeys produce long series of loud and low-pitched alarm roars in response to a number of disturbances, including the presence of leopards (Panthera pardus) and crowned eagles (Stephanoaetus coronatus), two of their main predators. We conducted a series of playback experiments, using vocalisations of the actual predators (leopard growls; eagle shrieks) and some corresponding primate alarm calls (calls of Diana monkeys, Cercopithecus diana, Campbell's monkeys, Cercopi-thecus campbelli, and chimpanzees, Pan troglodytes). Black-and-white colobus monkeys regularly responded to these stimuli by producing alarm roars. We found that the duration of individual roars and inter-roar intervals differed as a function of the suspected predator type present. Roars in response to eagle-related stimuli were significantly longer than roars to leopard-related stimuli. In contrast, inter-roar intervals were significantly longer when leopard-related, rather than eagle-related, stimuli were played back. We also found a number of structural differences in the frequency parameters between eagle and leopard roars. Our results provide the first demonstration of predator-specific alarm calls in a colobine species, suggesting that the ability to label predator category might be relatively widespread throughout the primate order. 


\title{
Orbital Frontation and Morphological Variability in Primates: Geometric Morphometric Analysis of the Upper Facial Structures in Anthropoidea
}

\author{
Emiliano Bruner, Luca Fiorenza, Giorgio Manzi \\ Dipartimento di Biologia Animale e dell'Uomo, University La Sapienza, Rome, Italy \\ E-Mail emiliano.bruner@uniroma1.it
}

Key Words: Orbital variability $\cdot$ Skull morphology $\cdot$ Anthropoidea $\cdot$ Multivariate
statistics

The anatomical and physiological adaptations characterising visual capabilities of primates are considered principal variables in the evolutionary radiation of the whole order. Orbital frontation is related to the reduction of the splanchnocranium and to stereoscopy, and affects overall skull architecture. Within this context, morphological variability in the orbital region of Anthropoidea has been analysed by means of multivariate techniques and spatial coordinates (geometric morphometrics) on a sample of 87 individuals. A Principal Components Analysis reveals a 'planar' morphospace, in which the first two components equally account for morphological variability. The first component explains a morpho-structural process of frontation, with posterior cranial widening, midsagittal reduction of the upper facial structures, and divergence of the optic foramina. This component is, as always, strongly size-related, depending in particular upon orbital height and neurocranial width. All Hominoidea are large animals and, therefore, particularly frontated, with Hylobates and Pongo showing greater frontation than expected from orbital dimensions. Ceboidea and Cercopithecoidea overlap entirely, except for Leontopithecus, which shows marked lateralisation because of its small size. The second component reflects a process related to orbital verticalisation, through posterior cranial widening, nasal and interorbital reduction, lengthening and slight convergence of the orbital axes, inferior orbital shift in a caudad direction, and glabellar protrusion. Cercopithecinae and Papioninae are the most verticalised taxa, in contrast with all Ceboidea and in particular Alouatta, because of its strong airorynchy. Also in Pongo, airorynchy leads to low verticalisation. The second principal component is related to the verticalisation index and to interobital width. Cercopithecoidea show inverse correlation between frontation and verticalisation, with Colobidae probably lying in the lower range of the low verticalisation/high frontation pattern. Platyrrhini show low values for both, and more heterogeneous phenotypic variability, most of all in such specialised taxa as Alouatta (airorynchy), Aotus (nocturnal) and Leontopithecus (dwarfism).

\section{Neurophysiological and Behavioural Aspects of Tool-Use Understanding in Macaques}

\author{
Pier Francesco Ferrari, Stefano Rozzi, Giacomo Rizzolatti, Leonardo Fogassi \\ Dipartimento di Neuroscienze, Università di Parma, via Volturno 39, 43100 Parma, \\ Italy \\ E-Mail ferrari@biol.unipr.it
}

Key Words: Mirror neurons $\cdot$ Action understanding $\cdot$ Macaque $\cdot$ Tool

It is traditionally acknowledged that in some apes the use of tools is a well established practice in wild populations. As far as monkeys are concerned, only a few observations of tool-use have been reported in the wild or in captivity and it has been reported mainly in macaques and baboons. Very little is known about which neurophysiological mechanisms underpin the ability of macaques to use tools and to understand actions performed with a tool. In a series of experiments, we found that in the ventral premotor cortex of pig-tailed macaques 
(Macaca nemestrina) there are visuomotor neurons that fire when the monkey observes an action performed with a tool by an experimenter. The tools used by the experimenter were a stick and pliers that were used to reach and retrieve pieces of food. However, when we carried out an experiment in which the tools were made available to the monkeys for collecting food out of reach, they did not succeeded in performing the behavioural task. As these neurons have properties similar to mirror neurons, which are located in this same area, it is possible to hypothesize that their visual response could represent the process of understanding actions performed with a tool. This suggests that macaques understand actions, in terms of their goal and meaning, although they are not present in their motor repertoire.

\title{
The Revision of the European Legislation on the Protection of Non-Human Primates Used for Experimental Purposes
}

\section{Gemma Perretta}

Istituto di Neurobiologia e Medicina Molecolare-CNR, Rome, Italy

E-Mail ims@casaccia.enea.it

\section{Key Words: European legislation • Welfare • Non-human primates}

The European Directive 86/609/CEE on the protection of animals used for experimental and other scientific purposes and the European Convention of the Council of Europe (ETS 123) set minimum standards for the housing and care of non-human primates used for experimental purposes within Europe. They also aim at reducing the numbers of animals used for experiments by encouraging the development and validation of alternative methods to replace animal use. Both legal requirements and guidelines are now under in-depth revision. The amendments will take into account the general lines of the current legislation, as well as the recommendations for the housing of non-human primates. The objective of the revision is to pay full regard to the welfare of animals with a higher degree of neurophysiological sensitivity such as non-human primates. In this respect, special attention is given to their behaviour, environmental and social enrichment as well as to the minimum dimensions of the enclosures. The revision processes will be briefly outlined, and the different criteria that should be considered when assessing housing design will be reviewed.

\section{Poster Session}

\section{Non-Human Primates at 'Parco Etologico di Corbaiola' (Radicondoli): A Project to Build a New Indoor/Outdoor Monkey Facility}

\author{
Monica Carosi ${ }^{\mathrm{a}, \mathrm{b}}$, A. Civai ${ }^{\mathrm{a}, \mathrm{b}}$, Roberto Cozzolino ${ }^{\mathrm{a}, \mathrm{b}}$ \\ ${ }^{\mathrm{a} E t h o i k o s ;}{ }^{\mathrm{b}}$ Centro Studi Etologici, Convento dell'Osservanza, Radicondoli (SI), Italy \\ E-Mail cse@centrostudietologici.it
}

Key Words: Monkey facility $•$ Behavioural research • Indoor/outdoor enclosures

A centre for the study of animal behaviour and ecology, 'Parco Etologico di Corbaiola', is going to be created in Radicondoli (Siena, Italy) on the grounds of the Podere Corbaiola and the surrounding 70 ha of woods. The centre will be available to researchers 
and students of any grade to study both local fauna, in its natural environment, and exotic species, namely non-human primates. Monkey species to be housed at the centre are the brown capuchin (Cebus apella) and a choice from the genus Macaca, maybe the Tonkean macaque (Macaca tonkeana), Barbary macaque (Macaca sylvanus) or Japanese macaque (Macaca fuscata). It is intended that a $2750 \mathrm{~m}^{2}$ monkey facility be built. In order to minimise the environmental impact, two separate facilities are planned, one for each species, which are connected through an outdoor roofed path. Each facility consists of indoor and outdoor areas. Indoor animal rooms are provided with either natural climate year round (sunlight, temperature, humidity) or a controlled physical environment, depending on specific needs (either research requirements or an adequate outdoor climate). The indoor area also includes separate rooms for animal husbandry and personnel needs (animal surgery, animal isolation, food storage, food processing, cage washing, storage, dressing-room, washing facilities, etc.) and also a reception area for visitors. Some animal husbandry and personnel rooms are supposed to be shared between facilities so that only one of the two indoor buildings will include some of them and will consequently be reduced in size. In both facilities, the outdoor area will be divided into a partially covered and protected outdoor enclosure (provided with connecting/capture tunnels) and a bigger, totally natural, area.

\title{
Observations on the Food Habits of the Endemic Udzungwa Red Colobus (Piliocolobus gordonorum) from Different Forest Sites in the Udzungwa Mountains, Tanzania
}

\author{
Alessandro Pucci ${ }^{\mathrm{a}}$, Francesco Rovero ${ }^{\mathrm{b}}$ \\ a'Dipartimento di Biologia Animale e dell'Uomo, Univ. degli Studi 'La Sapienza', Rome, \\ Italy; ${ }^{b}$ Museo Tridentino di Scienze Naturali, Trento, Italy \\ E-Mail ale@lifejackets.it
}

Key Words: Diet composition • Feeding ecology $・$ Red colobus $\cdot$ Udzungwa Mountains

The Udzungwa red colobus (Piliocolobus gordonorum, or P. badius gordonorum) is an IUCN Endangered species, or subspecies, endemic to moist forests of the Udzungwa Mountains $\left(10,000 \mathrm{~km}^{2}\right)$, Tanzania, which are part of one of the 25 globally important 'Biodiversity Hotspots'. Information on the Udzungwa red colobus is extremely scant and insufficient for the design of appropriate conservation management plans. Information on feeding ecology in relation to different habitat types and quality is particularly relevant, because it is crucial to know how the species responds to the habitat degradation and destruction that severely affect its current range. This study presents the results of observations conducted on feeding behaviour over a period of 6 months on selected red colobus groups from a range of forest sites (from lowland, semi-deciduous forest to sub-montane, mature evergreen forest) characterised by various levels of habitat degradation (from severely degraded to pristine forest). Observations on the food items that red colobus fed upon were conducted through scan sampling techniques, complemented by opportunistic records, for about 2-3 days per group per month. Preliminary results are presented here in terms of diet composition and variation of food habits with habitat quality. A large variety of plant parts was included in the diet, dominated by young and mature leaves (about 70\%); the number of plant species included in the diet varied for each group (range of 15-50 species of both trees and lianas), but as few as 5-6 species accounted for $75 \%$ of the diet. Red colobus show great flexibility and adaptability with respect to food resources even in small and broken forest patches of less than $1 \mathrm{~km}^{2}$. However, both this study and other available information show that reduced habitat quality affects group density, group size, group composition and recruitment, and therefore it is concluded that areas of closed-canopy forest are crucial for the long-term survival of this endangered and endemic species. 


\title{
Demographic and Reproductive Parameters in Captive Tufted Capuchins (Cebus apella)
}

\author{
M. Cristina Riviello, Annarita Wirz \\ Institute of Neurobiology and Molecular Medicine. C.N.R., Rome, Italy \\ E-Mail riviello@nembo.net
}

Key Words: Demography • Reproduction • Capuchin monkey $\cdot$ Cebus apella

Knowledge of demographic and reproductive parameters of wild and captive primates allows a better understanding of their biology, ecology and behaviour, thus improving the management of captive colonies. Here we present the results of a 19-year demographic analysis of a colony of capuchin monkeys (Cebus apella) born and maintained in captivity at the Primate Centre of C.N.R. (Rome, Italy). Information on reproduction, interbirth interval (IBI) and sex ratio is considered. The colony was founded in 1984 and consisted of 7 monkeys, 3 males and 4 females, given to us by Rome Zoo. At present, our Centre holds 33 monkeys, 14 males and 19 females. Over the years, 44 offspring have been born in the colony. To optimise the management of the animals in the limited space available, different contraceptive methods have been used. The age of females at first birth is between 5-7 years, the age of males at first breeding is between 5-9 years. Multiple births are very rare, with only one set of twins recorded. The mean IBI is $17.24 \pm 4.82$ months for females when they reared their infants, and $12.16 \pm 4.45$ months when they did not rear their offspring. Infant mortality within the first six months is $29.55 \%$. The offspring sex ratio is nearly $1: 1(1.09: 1$ $\mathrm{M}: \mathrm{F})$.

\section{Manual Asymmetries in Tufted Capuchin Monkeys (Cebus apella): The Use of Digits for Extracting a Small Food Item from a Narrow Aperture}

\author{
Tiziana Lagan, Valentina Truppa, Giovanna Spinozzi \\ Istituto di Scienze e Tecnologie della Cognizione, C.N.R., Unità di Primatologia \\ Cognitiva e Centro Primati, Rome, Italy \\ E-Mail spinozzi@pml.it
}

Key Words: Hand preference $\cdot$ Manual performance $\cdot$ Cebus apella

Capuchins (Cebus spp.) stand out among New World monkeys for their high degree of manual dexterity that enables them to grasp precisely and manipulate skilfully small objects. This dexterity is due to their ability to execute, to some extent, independent movements of the digits. The aim of this study is to describe how tufted capuchin monkeys (Cebus apella) remove a small food item from a tube focusing, in particular, on the differential use of the fingers for food retrieval, hand preferences, and inter-manual differences in the time the monkeys took to obtain the food (i.e., the latency to grasp). Tufted capuchins $(n=20)$ mainly used the forefinger $(63.5 \%)$ for extracting the food from the tube. The simultaneous use of the index and the middle finger was less frequent (26.2\%), whereas the use of the forefinger in combination with two other digits was rare. Hand preference analysis failed to reveal any significant lateral bias for the group: both adults ( $\geq 5$ years) and immature individuals $(<5$ years $)$ of both sexes used either hand with the same frequency. Conversely, latency analysis showed a significant interaction between performance difference between hands and the subject's age: in adults, but not in immature individuals, the left hand was faster than the right hand for food retrieval. 


\title{
Habitat Preferences and Ranging Behaviour of a Wild Group of Mico argentatus (Linnaeus, 1766)
}

Cecilia Veracini

Laboratori di Antropologia, Univ. of Florence, Italy

E-Mail cpfveracini@yahoo.com

Key Words: Mico argentatus $・$ Callitrichidae $\cdot$ Ranging behaviour $\cdot$ Amazonia

Home range size and ranging behaviour are very variable in callitrichids, often being different in similar species and in populations of the same species. A wide array of factors can influence callitrichids' ranging behaviour: metabolic rates, food habits and distribution of natural resources, presence of other primate species, density of the species and habitat degradation. The understanding of habitat use and ranging patterns is very important in the Amazonian marmosets (genus Mico) due to the growing habitat fragmentation of Amazonia. Moreover Amazonian marmosets seem less abundant than in the past. This work describe the ranging behaviour and habitat preferences of a wild group of silvery marmosets (Mico argentatus), studied in the Eastern Amazonia (Estação Cientifica Ferriera Penna-Caxiuanã/ $\mathrm{CNPq}, \mathrm{Pa}$, Brazil) for 11 months. The home range of M. argentatus was 15.5 ha in size, with a core area of $2.25 \mathrm{ha}$. The core area, situated in the centre of the home range, included the main gum and fruit sources of the study group. The estimated distance travelled by the group during the day varied from $630 \mathrm{~m}$ to $1710 \mathrm{~m}$. The mean distance travelled per day was $1030 \mathrm{~m}$. The group used very dense vegetation both in primary and in secondary habitats. The study group used secondary growth forests (capoeiras) of different growth levels for $78 \%$ of the observation time and primary and edge areas for the rest of time, without a significant seasonal variation (Wilcoxon-Mann-Whitney test, $\mathrm{p}>0.05$ ). Marmosets used several heights in the forest $(0-35 \mathrm{~m})$ with a preference for the middle-low strata $(6-15 \mathrm{~m})$. In the study period, the group used 14 different sleeping sites; the most visited were localised in the 'core area'. The home range size and the concentration of daily activity around the exudate sources found in M. argentatus are characteristics found in the marmosets considered more exudativorous than frugivorous. These results are in agreement with the study by Albernaz (1993) carried out in Alter do Chão (Pa) on the same species.

\section{Bonobo Social Behaviour: A Long-Term Research Proposal}

\author{
Tommaso Paoli ${ }^{\mathrm{a}}$, Elisabetta Palagi ${ }^{\mathrm{a}, \mathrm{b}}$, Benedetta Balsotti ${ }^{\mathrm{a}}$, Samuele Galli ${ }^{\mathrm{a}}$, \\ Giorgia Tacconi a , Silvana Borgognini Tarli \\ ${ }^{a}$ Dipartimento Etologia, Ecologia ed Evoluzione, Unità di Antropologia; ${ }^{\mathrm{b}}$ Centro \\ Interdipartimentale Museo di Storia Naturale e del Territorio, Univ. of Pisa, Italy \\ E-Mail t.paoli@deee.unipi.it
}

Key Words: Conflict management $\cdot$ Hierarchy $\cdot$ Affinitive behaviours $・$ Play $\cdot$ Sexual behaviour $\cdot$ Pan paniscus

The present project is based on a longitudinal study of the colony of bonobos (Pan paniscus) housed in the Apenheul Primate Park (Apeldoorn, The Netherlands). Behavioural data on the study group were collected during four observation sessions (between July 2000 and July 2003) with the aid of the following sampling methods: focal animal sampling, scan sampling, all occurrences. We collected a large quantity of data. Analyses are still in progress in order to understand further some major aspects of bonobo social behaviour: 
- Hierarchy - Knowledge of bonobo hierarchy is controversial: some authors define it as 'fairly linear', with dominant females; others have found male/female co-dominance and that hierarchical relationships are not clearly defined.

- Affiliative behaviours (with special regard to food sharing and peering) - The patterns of affiliation among bonobos have been described by many authors, but there is not full agreement on this issue. Moreover, it is still necessary to look in depth at 'how and when' food sharing and peering behaviours are employed.

- Play behaviour - Play behaviour in bonobos has been studied from only a descriptive point of view: therefore a quantitative analysis of playful patterns is still required.

- Sexual behaviour - Bonobo sexual behaviour has been emphasised for its nonreproductive context and its peculiar repertoire, but the role of hetero- and homosexual contacts as a social strategy still needs to be singled out.

- Conflict management - Data on conflict management in this species are limited to date, consequently we aim to re-evaluate and clarify the occurrence of reconciliation, and investigate the presence of consolation and buffering mechanisms to avoid the conflict spreading.

Therefore, the aim of this project is to acquire a global view on the social behaviour of bonobos by studying the above aspects and their reciprocal inter-connections.

\title{
Behavioural Responses to Conspecifics' Scent Marks in Lemur catta: a Research Project
}

\author{
Sabrina Telara ${ }^{\mathrm{a}}$,Elisabetta Palagi ${ }^{\mathrm{a}, \mathrm{b}}$, Ruth Correli ${ }^{\mathrm{a}}$, Paola Garbasi ${ }^{\mathrm{a}}$, Luca De Santi ${ }^{\mathrm{a}}$, \\ Silvana Borgognini Tarli ${ }^{\mathrm{a}}$ \\ a Dipartimento di Etologia, Ecologia ed Evoluzione, Unità di Antropologia, Univ. of Pisa; \\ ${ }^{b}$ Centro Interdipartimentale Museo di Storia Naturale e del Territorio, Univ. of Pisa, \\ Italy \\ E-Mail sabrina.telara@inwind.it
}

Key Words: Olfactory stimuli $\cdot$ Scent marking $\cdot$ Discriminatory response $\cdot$ Lemur catta

Olfaction plays an important role in Lemur catta social communication. In fact, many aspects of intra-group sociality, such as reproductive activity, competition, and dominance relations, are mediated by olfactory communication, which consists of both investigation and scent marking behaviours. This research is part of a chemo-behavioural study of olfactory communication in 12 captive ring-tailed lemurs held at Pistoia Zoo (Tuscany, Italy). The colony is divided into three groups made up of seven, three, and two individuals. Our aim was to examine the behavioural responses of ring-tailed lemurs to specific olfactory stimuli released by conspecifics in order to shed light on the discrimination of scent markings (both male and female genital mark and urine mark, while males wrist mark, and wrist to pit + wrist mark) and on the seasonal fluctuation of such responses. In order to collect the olfactory secretions (stimuli), we placed filter paper on special supports and the lemurs (donors) marked these spontaneously. The filter paper with the donors' scent was then fixed on special wooden sticks. Immediately after collection, the wooden stick with the scent and an identical stick without odour (control) were presented to the receiver. Subsequently, to test for the discriminatory responses, we presented two different kinds of scent mark in every possible combination. Each scent-test lasted five minutes during which the observer recorded the animal interacting with the sticks, the exact duration of the sniffing and licking session, and the occurrence of marking activity (type and frequency). Data collection and preliminary analyses are in progress. 


\title{
The Role of the Endocrine System in Macaque Maternal Behaviour
}

\author{
Massimo Bardi ${ }^{a}$, Keiko Shimizu ${ }^{b}$, Gordon M. Barrett ${ }^{b}$, Michael A. Huffman ${ }^{b}$, \\ Silvana M. Borgognini-Tarlic \\ aDepartment of Comparative Medicine, Southwest Foundation for Biomedical Research,

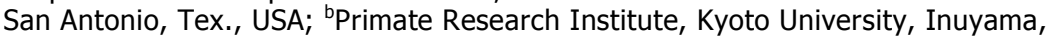 \\ Japan; 'Department of Ethology, Ecology, Evolution, University of Pisa, Italy \\ E-Mail mbardi@icarus.sfbr.org
}

Key Words: Rhesus macaque - Japanese macaque • Ovarian steroids • Adrenal steroids • Mother-infant interactions

Despite an increasing number of studies assessing the role of the endocrine system in the shaping of social and infant-directed behaviours during the peripartum period, contradictory evidence still exists on the extent of the effects of endocrine changes on the priming of maternal care in primates. A four-year study on the physiological correlates of maternal and social behaviour in two macaques species pointed towards the importance of the whole endocrine system as a functional unit in terms of enhancing maternal care in primates. The dramatic physiological changes occurring during late pregnancy and early lactation are clearly primarily functional for parturition itself, and may act, secondarily, in coordination with the cognitive/experiential system in helping the mother to cope with the additional problems imposed by the newborn. We used enzyme immunoassays (EIAs) to measure levels of excreted gonadal and adrenal steroids, including cortisol, pregnanediol-3-glucoronide $(\mathrm{PdG})$ and various oestrogen conjugates $\left(\mathrm{E}_{1} \mathrm{C}\right)$ in 24 subjects. Mother-infant interactions and female social behaviours during the peripartum periods were monitored extensively for over 2,000 hours. Our results showed a clear negative association between the oestrogen/ progesterone ratio and the timing and intensity of maternal rejection, as well as an association with some affiliative behaviour changes. The role played by the adrenocortical hormones followed a dual pathway. On the one hand, psychogenic stressors that may result in fear or anxiety were associated with elevated adrenocortical production of glucocorticoids and, therefore, high cortisol levels had a negative impact on the emotional status of the mothers. On the other hand, prepartum increase in oestrogen levels and the association with high levels of glucocorticoids during pregnancy may be linked to adaptive behavioural modifications preparing mothers for the interaction with their newborn. Therefore, when hypercorticolism during lactation lasted for more than a few days, psychogenic stressors prevailed, as is the case for many forms of psychiatric disturbances during the postpartum period.

\section{Vocal Repertoire of Alouatta palliata mexicana in Agaltepec \\ Giovanni Boscarol ${ }^{\mathrm{b}}$, Silvia Piazzab ${ }^{\mathrm{b}}$ Chiara Pizzigalli ${ }^{\mathrm{b}}$, Ivonne Falcone ${ }^{\mathrm{a}}$, Marco Gamba ${ }^{\mathrm{a}}$, Loredana Martinoli $^{c}$, Raffaella Fiore ${ }^{c}$, Ernesto Rodriguez Luna ${ }^{\mathrm{d}}$, Cristina Giacoma ${ }^{\mathrm{a}}$ \\ ${ }^{a}$ Dipartimento di Biologia Animale e dell'Uomo, University of Turin, Turin; ' University of Milan; 'Associazione Pithekos, Milan, Italy; ${ }^{d}$ Universidad Veracruzana, Instituto de Neuroetologia, Xalapa, Veracruz, Mexico \\ E-Mail potto@tiscali.it}

Key Words: Howler monkeys • Vocalisation • Roar • Woof

Despite being one of the most studied primate genera in the world, many aspects of the Alouatta species biology are still undiscovered. We studied Alouatta palliata mexicana, a Mesoamerican howler monkey. Data collection took place in Agaltepec Island, a protected 
area of the 'Parque de la flora y fauna sylvestre tropical' in the Los Tuxtlas region (Veracruz) Mexico. A community of 80 individuals lives on the 8 ha island. Each individual was identified by some yellow stains visible on the hands, feet and tail. The peculiar vocal behaviour of this species is due to the particular morphology of its hyoid bone, strikingly bigger in males. Our aim was to describe the vocal repertoire of this species. Visual investigations of the spectrograms of the vocalisations showed there were at least four groups of vocalisations to which most of the emissions by males can be assigned to: Roars, Incipient Roars, Woofs, Incipient Woofs. Other vocalisations were classified as Oodles, still by males, Caws, Heh and Maou, by subadults and females. The Oodle is frequently emitted at the end of the Roar and consists of a rapid series of acoustic units emitted both during exhalation and inhalation. Roars are extremely loud calls emitted by males, often occurring in choruses with several individuals involved. The Incipient Roars are pulsating emissions, frequently emitted before the Roar, but are seldom given as stand-alone vocalisations. Woofs are usually emitted in series. To categorise Woofs, we separated the recorded sequences into two groups. One was built over the series that features exhaled Woofs only, the other includes series that features Woofs emitted both during exhalation and inhalation. By spectrogram analysis we found that Woofs can also occur as a double or triple unit, without interval. According to these unit types, we recognised 74 different patterns over 105 sequences.

\title{
Early Vocalisations in Two Different Human Primate Ethnic Groups
}

\author{
Barbara Ruzza ${ }^{a, b}$, Francesca Roccac,, , Daniela Lenti Boero ${ }^{b, d}$, Carlo Lenti ${ }^{b, e}$ \\ a'San Paolo Hospital, Univ. of Milan; 'baboratory of Bioacoustics and Comparative \\ Analysis of Behaviour and Cognitive Functions, Univ. of Milan; 'Department of \\ Paediatrics, Univ. of Milan; ${ }^{\mathrm{d}}$ Faculty of Pedagogical Sciences, Univ. of Urbino; \\ ${ }^{e}$ Chair of Child Neuropsychiatry, Univ. of Milan, Italy \\ E-Mail libaru@katamail.com
}

\section{Key Words: Early vocalisation $\cdot$ Speech sounds $\cdot$ Acoustical analyses}

The aim of this study was to explore the differences between the early vocalisations of two different ethnic groups: Italian and Moroccan. The subjects of this study were six two month old infants: three Moroccan (female) and three Italian (1 male, 2 female). All the infants were born full term and had normal parameters at birth. The vocalisations were recorded in the infant's home while the subject interacted with its mother, the investigator and, only for the Moroccan babies, a cultural mediator. Vocalisations were recorded with a DAT sound recorder and a microphone and acquired by means of the Software Pro Tools. Recordings were subdivided into frames lasting from 6 to $12 \mathrm{~s}$ each. Each frame was analysed with Software Canary 1.2. We used the Software SYSTAT 10 for statistical analysis of acoustic parameters. In both samples (Italian and Moroccan), there were more speech utterances than non-speech sounds: $74 \%$ speech versus $26 \%$ non-speech for Italian infants and $66 \%$ speech versus $34 \%$ non-speech for Moroccan infants. Both Italians and Moroccans used the same typologies of vocalisations, but the relative percentages were different: in the Italian sample quasi-vowel (cooing) (45\%) and vowel-like (27.7\%) predominated, while in the Moroccan sample vowel-like (46.5\%) and cooing (36.6\%) were prevalent. The comparison of speech-sound typologies showed that the two ethnic groups had different vocal expressions, perhaps due to the different kinds of stimulation from the mothers. Furthermore, for all vocalisations, we obtained the means of time and frequency parameters and the discriminant functions characteristic of each individual subject and both ethnic groups. This study shows evidence of the existence of speech sounds in the first two months of life. 


\title{
Anatomical and Morphological Notes on the Cranium of Piliocolobus gordonorum, Matschie 1900 (Udzungwa Red Colobus)
}

\author{
Emiliano Bruner ${ }^{a}$, Alessandro Pucci ${ }^{a}$, Trevor P. Jones ${ }^{b}$ \\ a'Dipartimento di Biologia Animale e dell'Uomo, University La Sapienza, Rome, Italy; \\ bUdzungwa Mountains National Park, Mang'ula, Tanzania \\ E-Mail emiliano.bruner@uniroma1.it
}

Key Words: African colobids $\cdot$ Skull $•$ Piliocolobus $・$ Udzungwa Mountains

The Udzungwa red colobus (Piliocolobus gordonorum, Matschie 1900), is an endangered Tanzanian colobid that suffered a major catastrophe as a result of habitat destruction due to construction of the railway, combined with extensive logging and agricultural expansion. Typically, it forms large groups numbering up to 50 animals, with territorial multi male - multi female units. Feeding is concentrated in two main sessions during the morning and the evening, and its diet is rather selective but heterogeneous (leaves, petioles, buds and fruits). Geophagy is rarely observed. This species is restricted to a few small forests on the Udzungwa Mountains (Eastern Arc Mountains, Tanzania), where it survives in riverine and mountane forest patches between 300 and 2,000 m asl. Very few groups are in Magombera and Kalunga forests, which are still isolated and rarely exploited. Two crania of $P$. gordonorum have been recovered and compared with morphological and anatomical data available in the literature. Both crania are well preserved and identified as belonging to fully adult females. The premaxillary sutures remain only partially fused almost to the point of frontal contact, as sometimes found in Piliocolobus badius. One specimen shows a unilateral spheno-parietal contact at the pterion. Internasal bones are limited but present. A clear infraorbital fossa is displayed. Three to four infraorbital foramina can be detected. Overall size is comparable to the mean value for P. badius. A cluster analysis based on ten metrical variables shows a phenotypic affinity to the same species (averaged values). A Principal Component Analysis confirms this result. In contrast, the two specimens are characterised by high length and width of the braincase, large bizygomatic width, and limited length and width of the muzzle. If size is removed, the two P. gordonorum show a phenotypic affinity with Procolobus verus (averaged values). The two crania have been compared by landmark data and Procrustes superimposition, showing very limited shape differences.

\section{Explorative Analysis on Airorynchy and Functional Morphology in the Skull of Alouatta, by Geometric Morphometric Techniques}

\author{
Emiliano Bruner, Simone Mantini, Giorgio Manzi \\ Dipartimento di Biologia Animale e dell'Uomo, University La Sapienza, Rome, Italy \\ E-Mail emiliano.bruner@uniroma1.it
}

Key Words: Airorynchy $\cdot$ Cranial structure $\cdot$ Alouatta $\bullet$ Superimposition

The skull in the genus Alouatta underwent a marked structural reorganisation related to the rotation of the splanchnocranium onto the neurocranial axis (airorynchy). This process has entirely remodelled the cranial functional matrix, and it has been hypothesised to be related to variables ranging from diet (mandibular ramus and masseter development) to behaviour and society (hyoid development and vocalisation). Landmark data (Generalised Procrustes Analysis, Euclidean Distance Matrix Analysis) are used here to compare the Alouatta skull with other taxa, to characterise differences and similarity. Compared with 
Brachyteles, the airorynchy of Alouatta is related to a strong neurocranial flattening involving muzzle flexion and enlargement, with backward (nuchal) shifting of the occipital foramen. In contrast, airorynchy in Pongo (compared with Pan) is related to an enlargement and flattening of the premaxilla-maxilla complex. Therefore, these two processes seem to be based on entirely different models. Some affinities can be detected between the Alouatta and the Aegyptopithecus structures, because of the muzzle development in the latter species. A pairwise comparison shows that in the Oligocene taxon the alignment between splanchnoand neurocranium is not associated to neurocranial flattening and movement of the occipital foramen. The phenotypic affinity can, therefore, be produced by different processes, namely a plesiomorphic muzzle development (Aegyptopithecus) and a derived airorynchy (Alouatta).

\title{
The Primatological Collection of the Doderlein Museum in Palermo, Italy
}

\author{
Luca Sineo \\ Dipartimento di Biologia animale - DBA, Univ. of Palermo, Via Archirafi 18, \\ 90123 Palermo, Italy \\ E-Mail Ilsineo@unipa.it
}

Key Words: Museum • Primatological collection

The Zoology Museum of the University of Palermo, recently named after Pietro Doderlein (1809-1895) houses a small but representative collection of primates, both Strepsirrhini and Haplorrhini. This primatological collection has been progressively assembled since the foundation of the Museum in 1862 until the 1960s. Serious attempts to sort and revise the collection have never been performed. The analysis of this collection (the catalogue includes 51 samples) has shown a great degree (53\%) of erroneous generic and/or specific attributions, together with a diffuse non-congruency between labels and catalogue. Further, visitors are not supplied with any information on geographical distribution, ecological features, conservation or systematics of the specimen. The aims of this study were revision of the whole collection, the biometrical and qualitative analysis of the samples and the creation of a didactic trail on primates and the evolution of hominids.

\section{Study of the Evolution of Human Chromosome 7 by Single Gene Mapping in Non-Human Primates}

\author{
Daniela Romagno ${ }^{a}$, Luca Sineo ${ }^{b}$ \\ aDipartimento di Biologia animale e Genetica 'Leo Pardi' Univ. of Florence. Italy; \\ 'Dipartimento di Biologia animale - DBA- Univ. Palermo, Palermo, Italy \\ E-Mail Ilsineo@unipa.it
}

Key Words: Chromosome $7 \cdot$ FISH $•$ Gene mapping $・$ Evolution $・$ Williams-Beuren syndrome $\cdot$ Non-human primates

Human chromosome 7 (HSA7) derives, by a pericentric inversion and a paracentric inversion, from an ancestral chromosome homologous to Pongo pygmaeus (PPY) 10. The evolution of this autosome during primate evolution is not clear. Even if chromosome painting shows that HAS7 synteny is highly conserved in the order Primates, high resolution GTG-banding analysis in Hominoidea and Cercopithecoidea indicates the occurrence of complex rearrangements during their evolution. In order to investigate the evolution of 
HSA7, we applied a monogenic probe FISH approach. This study reports on the chromosome mapping of Williams-Beuren syndrome locus (WS - HSA 7q11.23) on different Cercopithecoidea, considered as outgroups: Macaca fascicularis (MFA), Cercopithecus (Chlorocebus) aethiops (CAE) and Trachypithecus cristatus (TCR) (Cercopithecoidea, Primates). The probe hybridises on all species tested and demonstrates the occurrence of rearrangements like fusion, fission and pericentric plus paracentric inversions respectively in MFA, CAE and TCR. A possible chromosomal phylogeny has been proposed. This study confirms that single locus mapping is a very efficacious tool for the analysis of chromosomal rearrangements as it provides the opportunity to have a fine molecular confirmation of proposed banding patterns homologies. Further, this is the first chromosome mapping of WS locus in Cercopithecoidea.

\title{
Didactic Experience in the Parco Zoo of Falconara Marittima (Ancona)
}

\author{
M.P. Bigatti ${ }^{\text {, }}$ B. Bovio ${ }^{\text {a }}$, R. Piccinini ${ }^{\text {b }}$

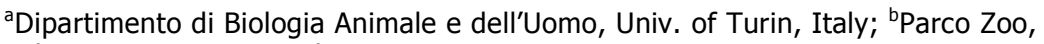 \\ Falconara Marittima, Italy \\ E-Mail mariapaola.bigatti@unito.it
}

Key Words: Zoos $・$ Didactics $・$ Primate management

During a natural science class in Turin University, research to improve knowledge of Italian institutes housing non-human primates was undertaken. In the Parco Zoo of Falconara Marittima the following species are present: Ateles fusciceps, Callithrix jacchus, Cebus apella, Chlorocebus aethiops and Lemur catta. A project to obtain information about major management aspects, such as welfare, feeding, sanitary checks and veterinary treatments, as well as participation in conservation and genetic protection programmes, was carried out. No particular management problems were observed and reproduction, lactation and parental care were successful. Moreover, no pathological behaviour caused by stress was observed during the fifteen days of observation (8-hours/day). Studies on enrichment conditions for Ateles fusciceps were also carried out. Preliminary results are presented. 